\title{
Application of Reservoir Performance Indices on Kainji Reservoir System
}

\author{
Mohammed Jiya Mamman ${ }^{1} \&$ Otache Y Matins ${ }^{2}$ \\ ${ }^{1}$ Department of Crop Production Technology, Niger State College of Agriculture Mokwa, Nigeria \\ ${ }^{2}$ Department of Agricultural and Bio resource Engineering Federal University of Technology Minna Niger State, \\ Nigeria \\ Correspondence: Mohammed JIYA MAMMAN, Department of Crop Production Technology, Niger State College \\ of Agriculture Mokwa, Nigeria. E-mail: ikwan1565@gmail.com
}

Received: April 15, 2020 Accepted: May 10, 2020 Online Published: May 27, 2020

\begin{abstract}
Resilience may be defined as a yardstick that specifies the extent a reservoir recuperates when it fails previously. A reliable water resource system speedily returns to an acceptable state after a failure. Vulnerability measures severity or extent of failures or letdowns, if and once they occur. Sustainability index (SI) provides a sign of fundamental nature with respects to probable unwanted repercussions if imbalance of waters occurs. Sustainability index (SI) can also be expressed as a mean of reliability, resilience and vulnerability. This study employs commonly used indices (reliability, resilience, and Vulnerability) to assess the performance of Kainji reservoir system. To attain this, rain fall and river flow data were obtained from Kainji Hydrological station in New Bussa Nigeria. Analysis using MAKESENS software was used on the rainfall and river flows to look at the extreme events. In order to determine the performance of the reservoir system some reservoir performance indices were employed, these are; vulnerability, resilience, and sustainability index. This is achieved by adopting relevant existing equations. Reservoir flows and storages ware employed, different draft ratios were considered (0.3- 1.0). Varying demand levels were also chosen $(0-0.8)$ as against the coefficient of variation to look at the monotonic behaviour of resilience against the various levels of demand. Volume reliability falls repeatedly as draft/ MAR upsurges and bigger values were attained as S/MAR rises. The analysis on the reservoir shows that as demand decreases the sustainability increases and also the higher the storage ratio the higher the sustainability index. It also shows that as draft ratio increases the resilience decreases, and because the draft ratio decreases the resilience increases. The reservoir system was classified as within year system, which suggests high resilience, less vulnerable and sustainable. The operation rule shows the need for optimization.
\end{abstract}

Keywords: reservoir, operation, inflow, outflow, storages randomness

\section{Introduction}

Reservoirs are hydraulic structures that play central role in the growth of any nation. It's the main costly element within the multiuse river basin in any geographical region. They require very cautious planning, design, construction, and operation (Yafang et al., 2019). A reservoir could be an artificial water catchment or big freshwater body which is employed for numerous purpose activities for example; hydropower generation, water system, and regulate flooding, to safeguard the environment. The challenges of the water system as a result of the probability factors like randomness of rainfall and runoff make the management of the reservoir system a difficult one.

The key reservoir measuring instruments are broadly applied tools to assess the effect of water resource systems on a lifelong position. In putting to use a water resource storing system, letdown is assumed to have happen when request at a precise period say four weeks surpasses water supply. As we change to the succeeding week's period, water storage mechanism may stay within letdown situation or can shift to attainment condition. Within a latter situation, present reservoir letdown is assumed overtaken. The reservoir letdown incident is categorized into two facets: amount of four weeks within which a specific incident occurs and plus the deficit.

Failures inside the operation of a reservoir have numerous facets: quantity, degree, severity. The aforementioned water resource measuring indicators are accustomed to quantify dissimilar parts as related to the effect of a reservoir mechanism. Typically the calculations of these indicators are done on monthly or yearly obtained figures (data). (Sharad, 2010). 


\subsection{Reliability}

largely water storage system rule operation are trailed in twofold indices. It is important to note that time, otherwise incidence centred on dependability of a water storage system can be described as the likelihood that a reservoir system state is within an acceptable positon.

$$
r_{t}=1-\left(\frac{f_{p}}{n}\right) ; 0 \leq r_{t} \leq 1, F_{p} . \leq n
$$

where $r_{t}=$ periodic dependability while $F_{p}=$ amount of letdowns times in all of the $\mathrm{N}$ times. $r_{v}=$ is given as Volume or quantity-based reliability

$$
r_{v}=V_{s} / V_{d}
$$

Where $\mathrm{Vs}=$ the quantity of supplied water and $\mathrm{V}_{\mathrm{d}}$ = quantity of water needed during a given time. Giving $\mathrm{N}$ as the all amount of letdown occasions. Stirring from periodic stage $t$ toward $(t+1)$, a reservoir shall whichever continue to be in the similar position or move to the other positon. A period of the $\mathrm{j}^{\text {th }}$ letdown events represented by $\mathrm{dj}$. plus $\mathrm{vj}$. is the conforming shortfall size determined by:

$$
E V_{j}=\sum_{t=1}^{d_{j}}\left[D_{t}-R_{t}\right]
$$

Where $\mathrm{D}_{\mathrm{t}}=$ target demand and $\mathrm{R}_{\mathrm{t}}=$ release from the reservoir for the month $\mathrm{t}$.

\subsection{Resilience}

Resilience(c) defines speed to which a water storage system (reservoir) is possibly going to recuperate after let down. It's the same as the mean likelihood of regaining after letdown of a distinctive solitary time phase and can this is equated to the opposite of the average time which the system uses when at undesirable condition:

$$
\gamma_{\text {mean }}=\frac{1}{N} \sum_{j=1}^{N} d_{j}
$$

Moy. et al., (1986) explained resilience in the context of highest sequential time period of system lasting in deficient poor suboptimal state. Whereas as reported in Kjeldsen and Rosbjerg (2004), resilience is the opposite of the utmost failure duration. This is often explained according as in equation (1.5).

$$
\gamma_{\max }=\underset{j}{\max }\left\{d_{j}\right\}^{-1}
$$

where $\gamma_{\max }=$ resilience, $d_{j}=$ number of failure states.

Relating to his research, Kundzewicz and Kindler (1995), explained that the quantification of resilience grounded on extreme values are more preferred instead of the average figure quantification for the reason that insignificant inconsequential events may bring down the average value. Kjeldseen and Rosbjarg (2004) juxtaposed the twofold guesstimates of resilience together through approximation by means of $0.90^{\text {th }}$ fractile for experimental Cumulative Distribution Function (CDF) of let-down period plus the shortfall capacity. They also promoted the application of extended chains of simulated data to get strong and dependable approximations.

According to Hazen, followed by Sodler, and Hurst (1985), presented one among the foremost beneficial indices of reservoir system performance, here defined the resiliency index as:

$$
m=\frac{(1-\alpha) \mu}{\sigma}=\frac{1-\alpha}{C v}
$$

where $\alpha=$ annual yield as a segment of the average yearly inflow $\mu, \sigma=$ discrepancy of the yearly inflows, and $\mathrm{Cv}=$ coefficient of variation of the yearly streamflow.

Figure 1.1 described the interactions among $\mathrm{m}, \sigma$ and $\mathrm{Cv}$ given in equation (1.10) and in line with Vogel (1996), Perrens and Howell (1972), the term which is the standardized inflow was also used by Hurst, after which the nondimensional index $\mathrm{m}$ has subsequently found use in both analytical investigations in "water storage theory" and in town findings of the storage-reliability-yield relationship. Vogel \& Stedinger (1987) recommended that so far $0 \leq \mathrm{m} \leq 1$, the system is overcomed by over-year behaviour, $\sigma$ while if $\mathrm{m}>1$, the resevoir can be said to be 
dominated by within-year behaviour. Systems that are having small resiliency (m near zero) can be said to be categorized to be of either larger values of Coefficient of variation or as yearly yield or both (fig. 1.1). in the same vain, water recourse systems that have values of $m$ close or beyond unity are very probable to fill-up once empty and therefore those kind of systems are more expected to show within-year in its place of over-year behaviour.

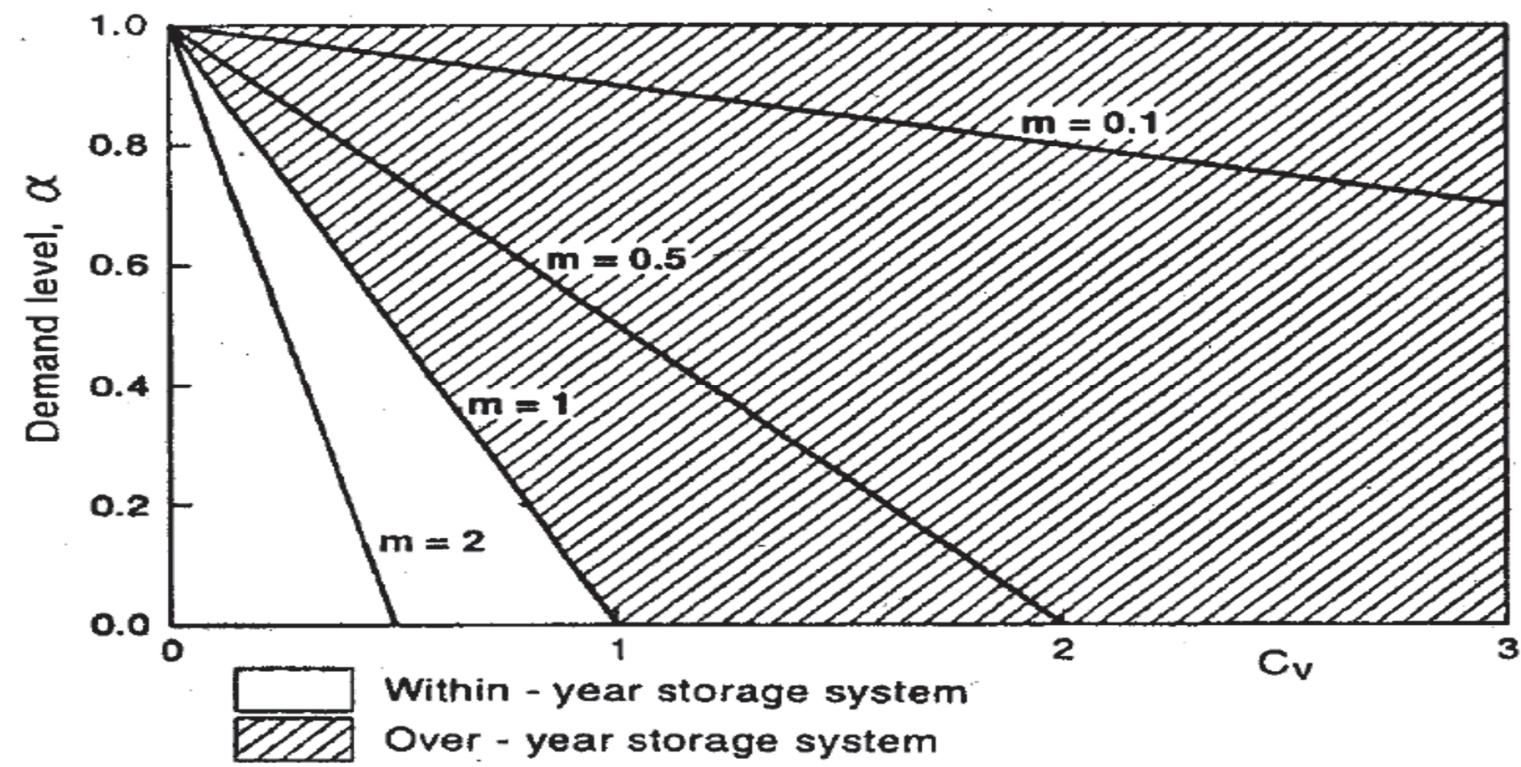

Figure 1.1 The demand level $\alpha$ as a function of the resiliency index $m$ and the Coefficient of variation of the inflows $C v$. (Richard, 1996)

\subsection{Vulnerability}

Vulnerability can be said to be a way of quantifying the impairment done in a failure event.

Kjeldsen and Rosbjerg (2004), projected vulnerability in the context of the average of the shortfall events Vj as:

$$
V_{\text {mean }}=\frac{1}{N} \sum_{j=1}^{N} V_{j}
$$

But Kundzewicz and Kindler (1995) suggested that the employment of a maximum event might yield a stronger estimate of vulnerability. To these effect, vulnerability may be computed as in equation (1.7).

$$
V_{\text {max }}=\max _{j}\left\{v_{j}\right\}
$$

Usually, Vmax is recorded in volume standard units. Mc-Mahon et al., (2006) employed non-dimensional vulnerability ratio by fractioning Vmax and objective demand. Hence, the existence of diverse methods to quantify resilience and vulnerability, reliant onto if the average or the utmost numeric magnitude of the variable signifying failure is accepted.

\subsection{Sustainability index (SI)}

Recently, some efforts were put up in order to measure the magnitude of how sustainable a reservoir will by adopting Resilience (R), Reliability (R) and Vulnerability (V). Zongxue et al., (1998), postulated a guide designated as drought risk index (DRI), which include the RRV:

$$
D R I=\beta_{1}\left(1-r_{t}\right)+\beta_{2}(1-\gamma)+\beta_{3}(1-V)
$$

where $\beta_{1}+\beta_{2}+\beta_{3}=1$. No procedures are accessible to select $\beta$ weights, however Loucks (1997) suggested an equation model termed sustainability index $(\mathrm{k})$ according as

$$
K=r_{t} \gamma\left(1-V_{\max } / \mathrm{D}\right)
$$

where $\mathrm{D}$ is termed draft, $\mathrm{V}_{\max }=$ vulnerability maximum, $\mathrm{V}=$ vulnerability.

Performance indices i.e. reliability, resilience, and vulnerability have been emphasised in several studies such as Moy et al., (1986), Kundzewicz and Laski (1995), Vogel and Bolognese (1995), Kundzaewicz and Kindller (1995), 
Thomas (2005) and Mc-Mahon et al., (2006). Zorica and Bojan (2017), Kang et a.,l (2019), Sharad (2010) and (Hui, et al 2019). The objective of this study was to adopt these indices for kainji reservoir system evaluation.

\section{Materials and Methods}

\subsection{Materials}

The hydrological data employed for this study were stream flow, rainfall and reservoir level.

\subsubsection{The Study Area}

By location, Kainji hydroelectric dam is situated in New Bussa in Niger State, Nigeria. The river is made behind the dam width between latitude $9^{\circ} 8^{\prime}$ to $10^{\circ} 7^{\prime}$ and between longitude $4^{\circ} 5^{\prime}$ to $4^{\circ} 7^{\prime}$ E. (Dukiya,2013). The mean yearly rainfall is $2200 \mathrm{~mm}$. Two types of rivers are identified, the black and white. The first drives its tributaries outside Nigeria peaking at about 2,000 $\mathrm{m}^{3} / \mathrm{sec}$ in February (Oyebande et al., 1992) and the second drive its source from local tributaries peaking at 4,000 to $6,000 \mathrm{~m}^{3} / \mathrm{sec}$ at September to October.

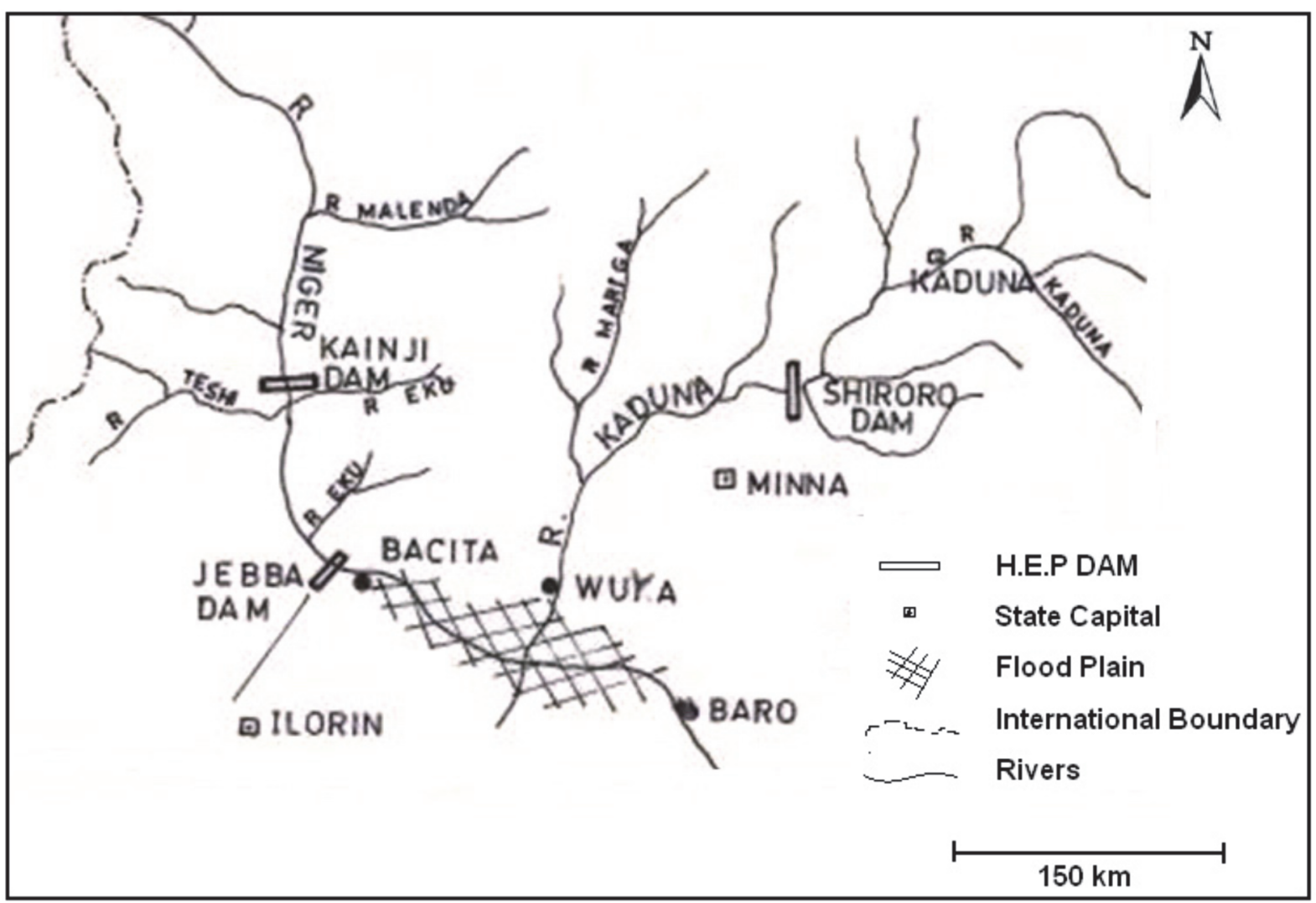

Figure 2.1. Position of Kainji Hydroelectric Dam.

Source: Salami: (2013)

\subsubsection{Source of Data}

This research is made of fluctuating time-based hydro - meteorological time sequence. It's constituted from monthly inflow and reservoir draw- down data for period of 25 (1990 to 2014) and 20 (1995 to 2014) years, correspondingly, monthly mean rainfall covering 50 (1965 to 2014) and 45 (1969 to 2013) monthly outflow were also acquired from the Hydrology section of Kainji dam, Niger state. A mean daily flow of $2280 \mathrm{~m}^{3} / \mathrm{sec}$ is demanded to sustain full generating capacity of 760MW (Alabaide, 2003). 


\section{Methods}

\subsection{Analysis of Reservoir Performance Indices}

\section{(i) Trend Analysis}

MAKESENS was use in estimating trends time series of the mean yearly and monthly (seasonal Mann- Kendall) rain fall, the reservoir level or draw - down and therefore the river flows. The obtained data sequences were divided into wet and dry period of year and twelve calendar months. The process is predicated on the nonparametric Mann-Kendall test for the trend and therefore the nonparametric Sen's technique for the extent of the variation.

\section{(ii) Volume Reliability Index}

The volume reliability or quantity based reliability $\mathrm{Rv}$ was estimated employing the equation below:

$$
\mathrm{Rv}=\mathrm{Vs} / \mathrm{Vd}
$$

Where Vs is the volume of water supplied and Vd is the volume of water demanded during a given period.

In determining volume reliability as a function of draft/MAF, different values of draft ratios were considered i.e., $(0.3-1)$, as in the works of Sharad (2010), this was to view the monotonic behaviour of volume reliability against draft/MAF.

\section{(iii) Sustainability Index}

The sustainability index was computed using the equation below:

$$
k=\frac{r_{t}\left(1-V_{\max }\right)}{D}\left(\frac{S_{\max }}{M A F}\right)
$$

where $\mathrm{r}_{\mathrm{t}}$ is the time reliability, $\mathrm{V}_{\max }$ is max Vulnerability, $\mathrm{D}$ is draft, $\mathrm{S}_{\max }$ is maximum storage, MAF is mean annual flow.

Different values of draft ratios were considered i.e., $(0.3-1)$, as in the works of Sharad (2010), this was to view the monotonic behaviour of sustainability index against draft/MAF.

\section{(iv) Resilience Index}

The resilience index which describes how quickly a system is probably going to pass though failure was evaluated employing the relationship:

$$
m=\frac{1-\alpha}{C_{V}}
$$

Where $m$ is the resilience, $\alpha$ is the demand level, and $\mathrm{C}_{\mathrm{v}}$ is the coefficient of variation. Different demand levels were chosen $(0-0.8)$ as against the coefficient of variation to view the monotonic behaviour of resilience against the different levels of demand.

\section{(v) Vulnerability Index}

Vulnerability which measures the likely magnitude of a failure was estimated using the equation below:

$$
V_{\text {mean }}=\frac{1}{N} \sum_{J=1}^{N} V_{j}
$$

where $\mathrm{v}_{\mathrm{j}}$ is the mean value of the deficit events, $\mathrm{N}$ is the period

\subsection{Classification of Reservoir System}

The reservoir system Characterization was carried out by using equation (1.16) as suggested in (Mohammed et al., 2018).

$$
\mathrm{m}=((1-\alpha)) / \mathrm{Cv}
$$

where and $m$ is referred to as the resiliency index, $\mathrm{CV}$ the coefficient of variation, whereas $\alpha$ is the demand. The resiliency index (m) was calculated by taking the ratio of demand subtracted from one and also the coefficient of variation $(\mathrm{CV})$; similarly $\mathrm{CV}$ was computed by taking the ratio of the standard deviation to the averages of the inflows. On the opposite hand, the demand levels were hypothetically fixed at $0,0.2,0.4,0.6$ and 0.8 in line with reservoir limit conditions (i.e. if $0 \leq \mathrm{m} \leq 1$, the reservoir system is dominated by over year behaviour, whereas if $\mathrm{m}>1$ ) the system is dominated by within - year behaviour) as recommended within the works of Vogel and 
Stedinger, (1987), Sharad (2010), and Issa et al., (2014). On the premise of this, two reservoir states were identified, (1) within - year storage (2) over - year storage.

\section{Result and Discussion}

\subsection{Reservoir Flow and Storages}

In describing the system flow and storages, Figure 3.1 presents monthly inflow storage and demand levels of kainji reservoir system. The smallest amount inflow was within the month of April and highest within the month of October. The month of October have peak outflow and storages. While maximum demand was within the month of September. The magnitude of the values obtained in September and October might be as results of peak rainfall within the time frame as might be observed in figure 3.6.

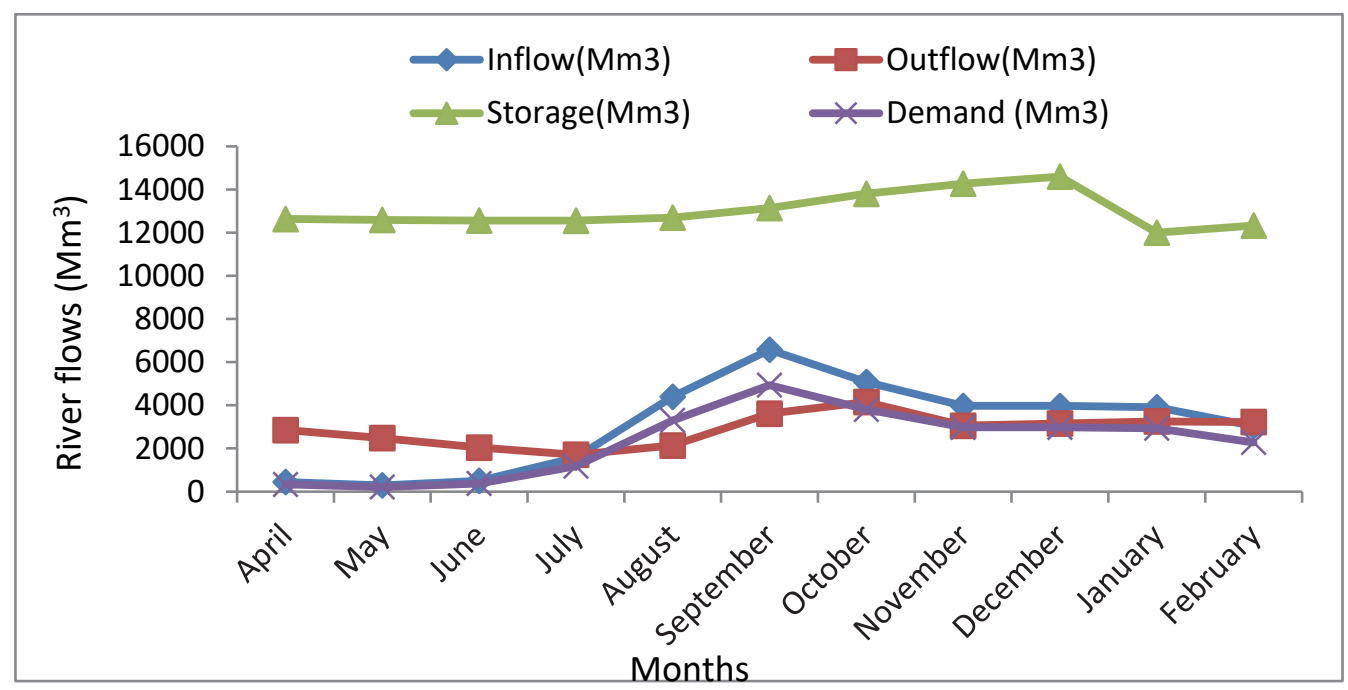

Figure 3.1. Monthly Inflows, Outflows, Storage and Demand Regime

Figure 3.2 illustrates the comparative disparity and dispersion within the averages of the rainfall respectively; it indicates the occurrence of seasonal effects within the moments, connoting that monthly statistics for dry season are considerably different comparatively from the raining season time regime. Distinct from irregular stream flow processes, the seasonal averages have greater values than the seasonal deviations all the years under consideration. The variance is maximum during lately rains and emerging dry season; more or less the interfacing period. This means atmospheric volatility during this watershed period; i.e., the fringes of the raining season moving into full Harmattan period.

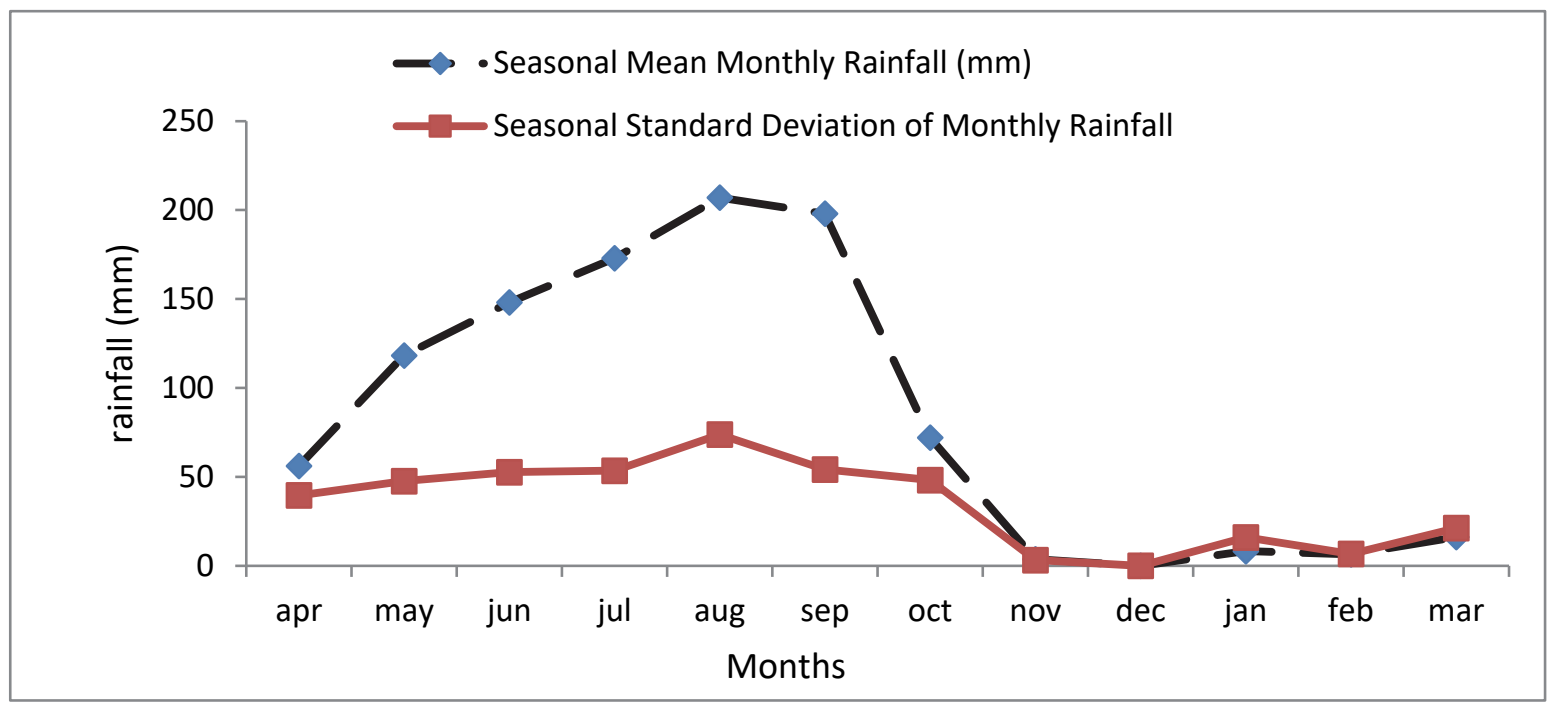

Figure 3.2. Variation in Seasonal Moments 


\subsection{Trend Analysis}

Figure 3.3 shows the inter- annual decadal variation within the rainfall series; long term pattern is apparently evident. However, there's large changeability among the monthly values of rainfall of various years, with the period 1985 - 1994 showing minor increases within the storm manifest during peak seasons.

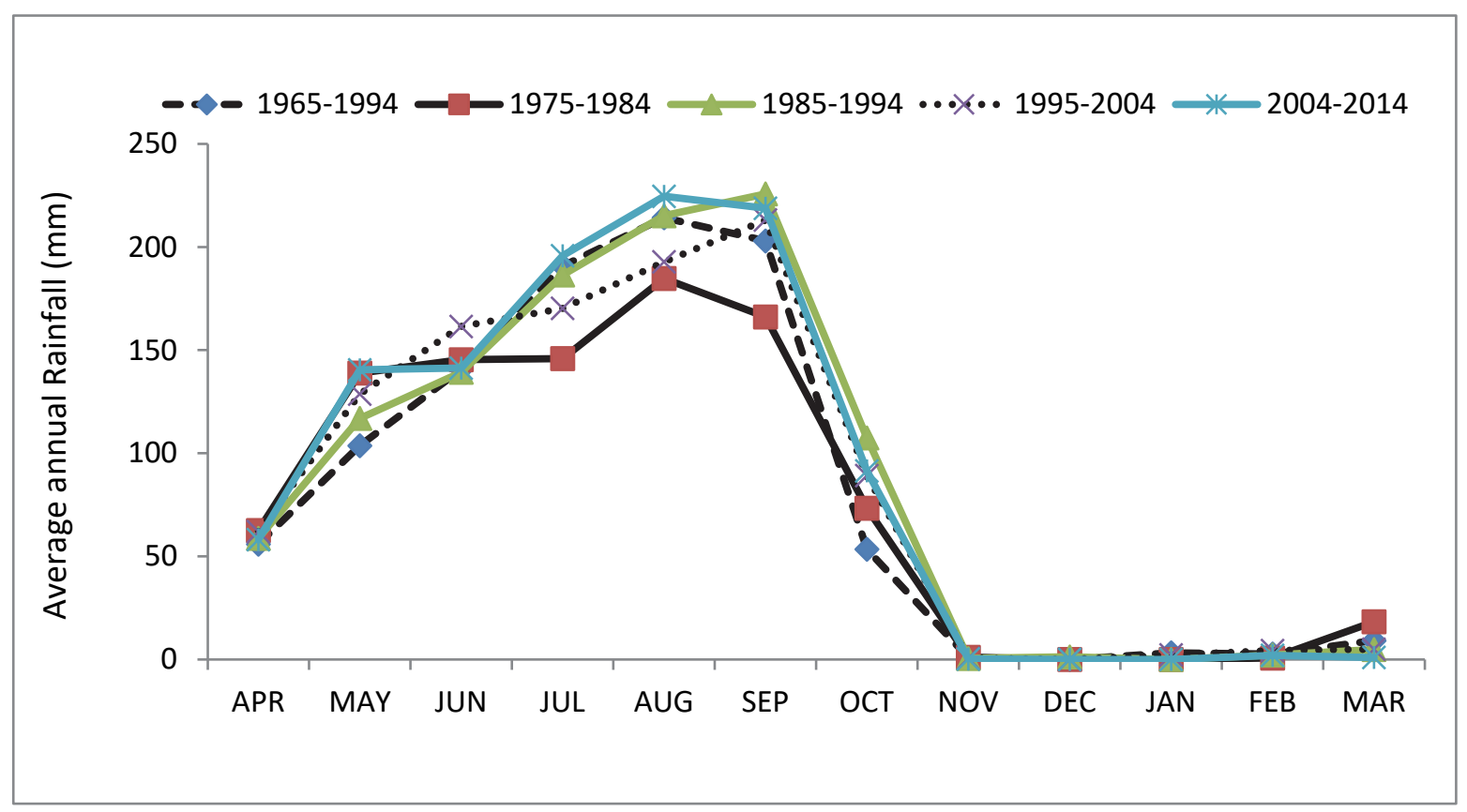

Figure 3.3. Inter- annual Variations in rainfall

The time - period of 1975 - 1984 shows all-time low rainfall decadal period. The rainstorm upsurges from the early raining period of April (hydrological period) of the year to the height period of September. The months of November to March shows dry periods.

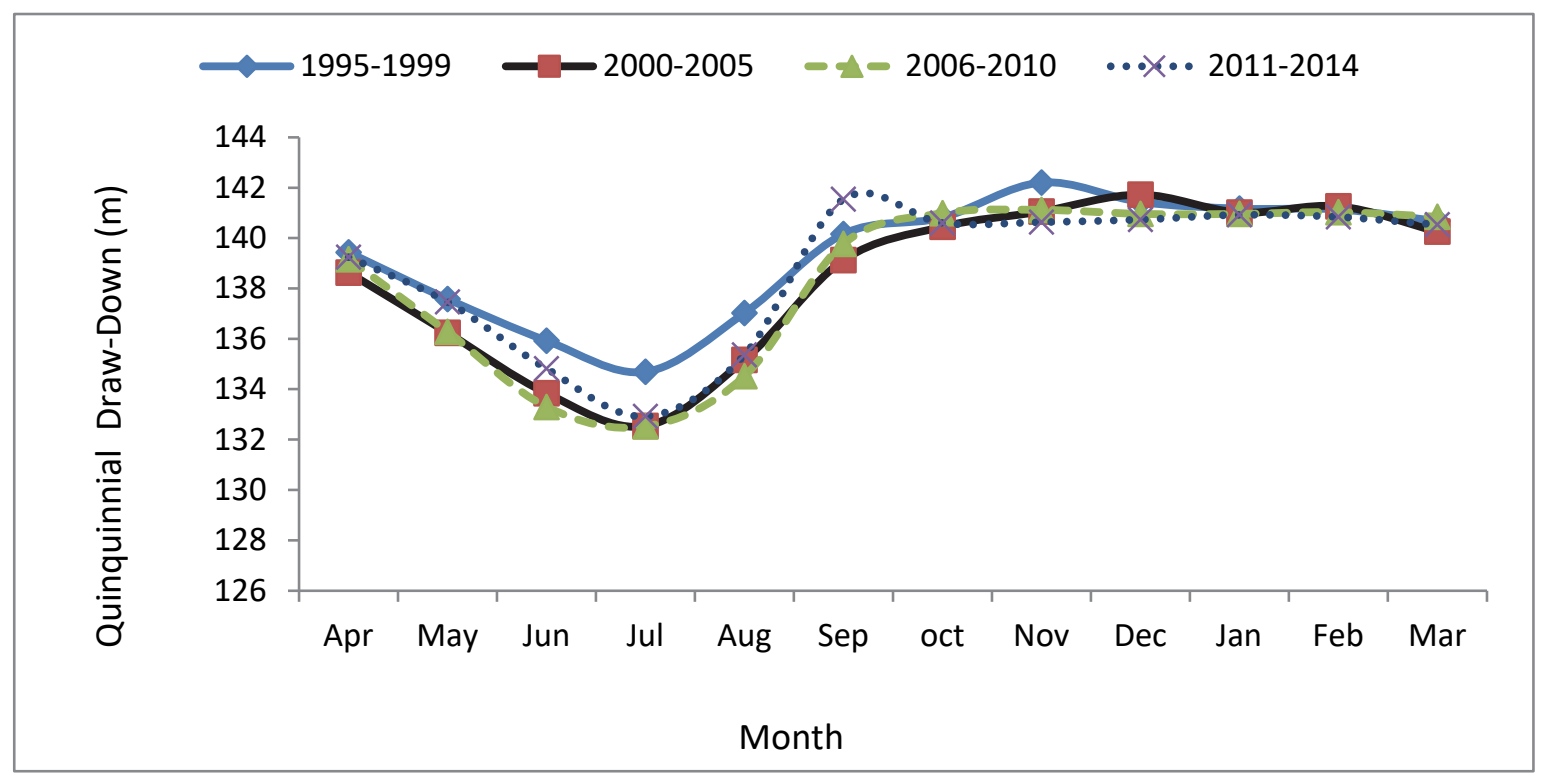

Figure 3.4. Trend of Average Monthly Draw - Down

Figure 3.4 and 3.5 display the five yearly intervals and ten yearly intervals mean annual draw- down of the reservoir. The lowermost reservoir level of $133.134 \mathrm{~m}$ was in the month of July and December getting the maximum reservoir level of $141.17 \mathrm{~m}$ throughout the time frame considered. The minimum reservoir level in July can be attributed to 
initial period of rainfall and therefore the maximum at the month of December can be accredited to extreme period of rainfall in August plus September.

Figure 3.5 describes the inter- annual decadal variation within the reservoir level; long term pattern is apparently evident. Also there's large inconsistency among the monthly values of reservoir level of various years, with the time period of $1995-2004$ showing slight increases within the draw-down with peak of $141.56 \mathrm{~m}$, evident during peak seasons. The water level of the reservoir is at very low level within the month of July with reservoir level at $132,66 \mathrm{~m}$ in 2005- 2014 time period. Figure 3.4 describe obviously seasonal or periodic pattern; it is a periodicstochastic series. The analysis of the step or jump trend of the reservoir draw - down indicates that the critical value $\mathrm{t} \_0.05(18)=1.734, \mathrm{t}=4.46$ in order that the hypothesis $\mathrm{H} 1$ is accepted, as $\mathrm{t}\left(\mu \_1 \neq \mu \_2\right)$, meaning that the step or jump trend is significant at $5 \%$ probability.

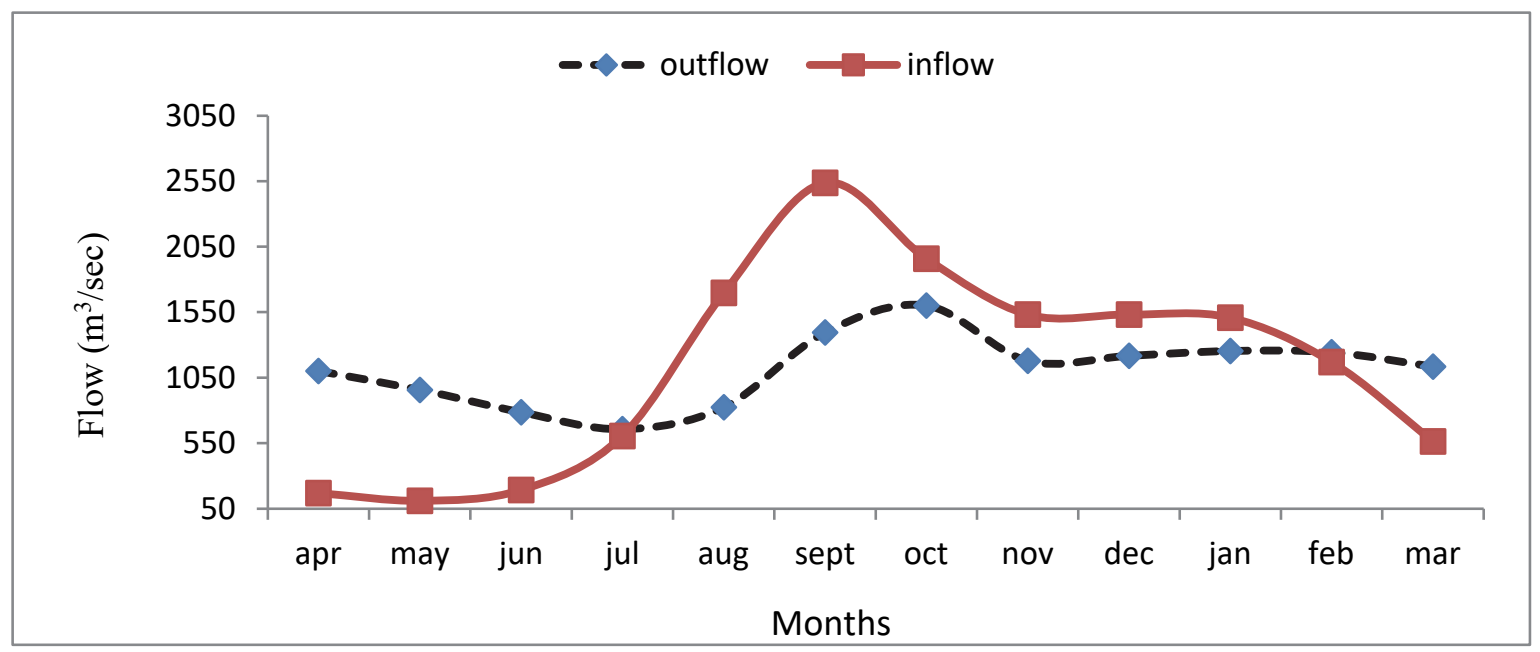

Figure 3.6. Trend of Monthly Flow of Kainji

The monthly reservoir flows i.e., inflow and outflow, is displayed in figure 3.6. The peak inflow was within the month of September with a maximum of $2516.39 \mathrm{~m} 3 / \mathrm{sec}$ during the time frame of peak storm. Similarly the outflow was at the highest within the month of October with a recorded value of $1456.98 \mathrm{~m} 3 / \mathrm{sec}$. The low flows recorded were within the periods of early rainstorm.

\subsection{Reservoir Operating Policy}

Figure 3.8. Shows operation rule of kainji reservoir system, it describes level of storages as it relates to months. The lowest storage was in the month of January with12000Mm3 and peaking at $14602.58 \mathrm{Mm} 3$ in December. The peak period in January could be attributed to heavy rainfall in the months of August, September and October as the flood which finds its way to the river far away from the dam in Nigeria. The reservoir could be said to be reliable looking at the storage capacity through the months but there is need to increase storages and reduce excessive demands by optimizing the operation policy. The gap between the antecedent operation policy and SLOP operation policy implies the need for increases in storages so as the increase the reliability of the reservoir. 


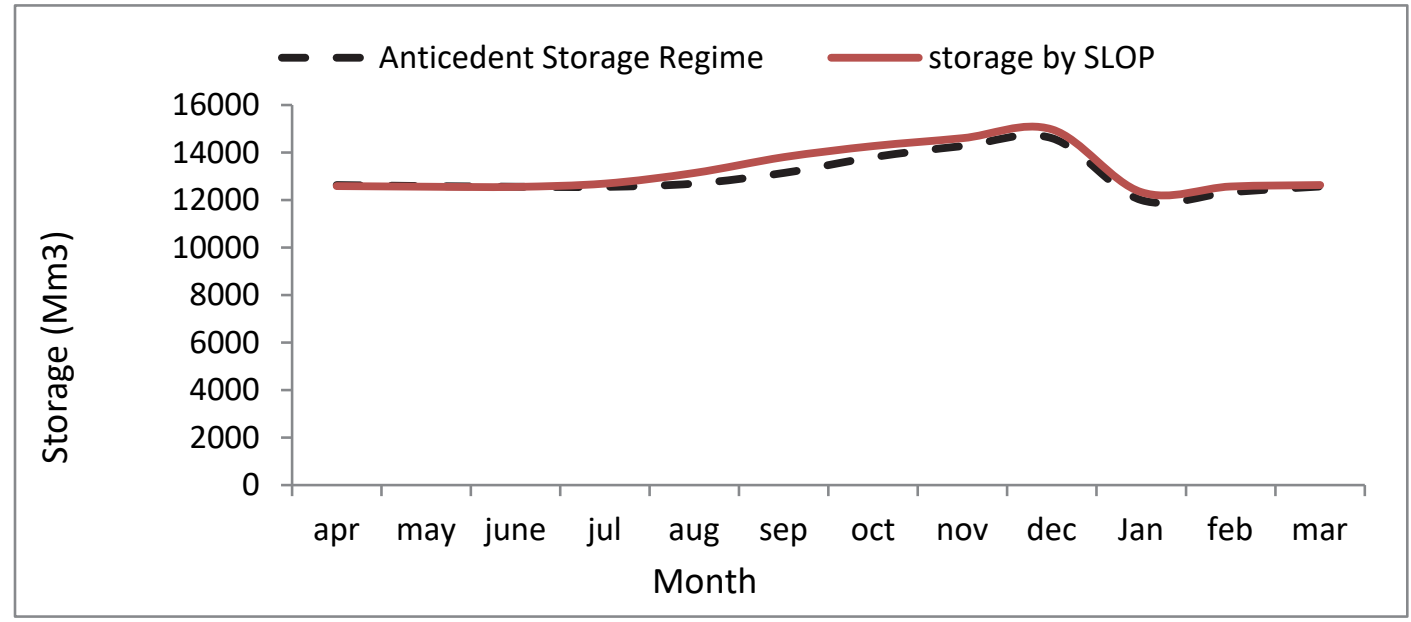

Figure 3.8. Kainji reservoir storage rule curve

\subsection{Reservoir Performance Indices}

(i) Volume reliability index

In order to establish the performance of the reservoir system some reservoir performance indices were employed, these are; vulnerability, resilience, and sustainability index. The results are as presented below.

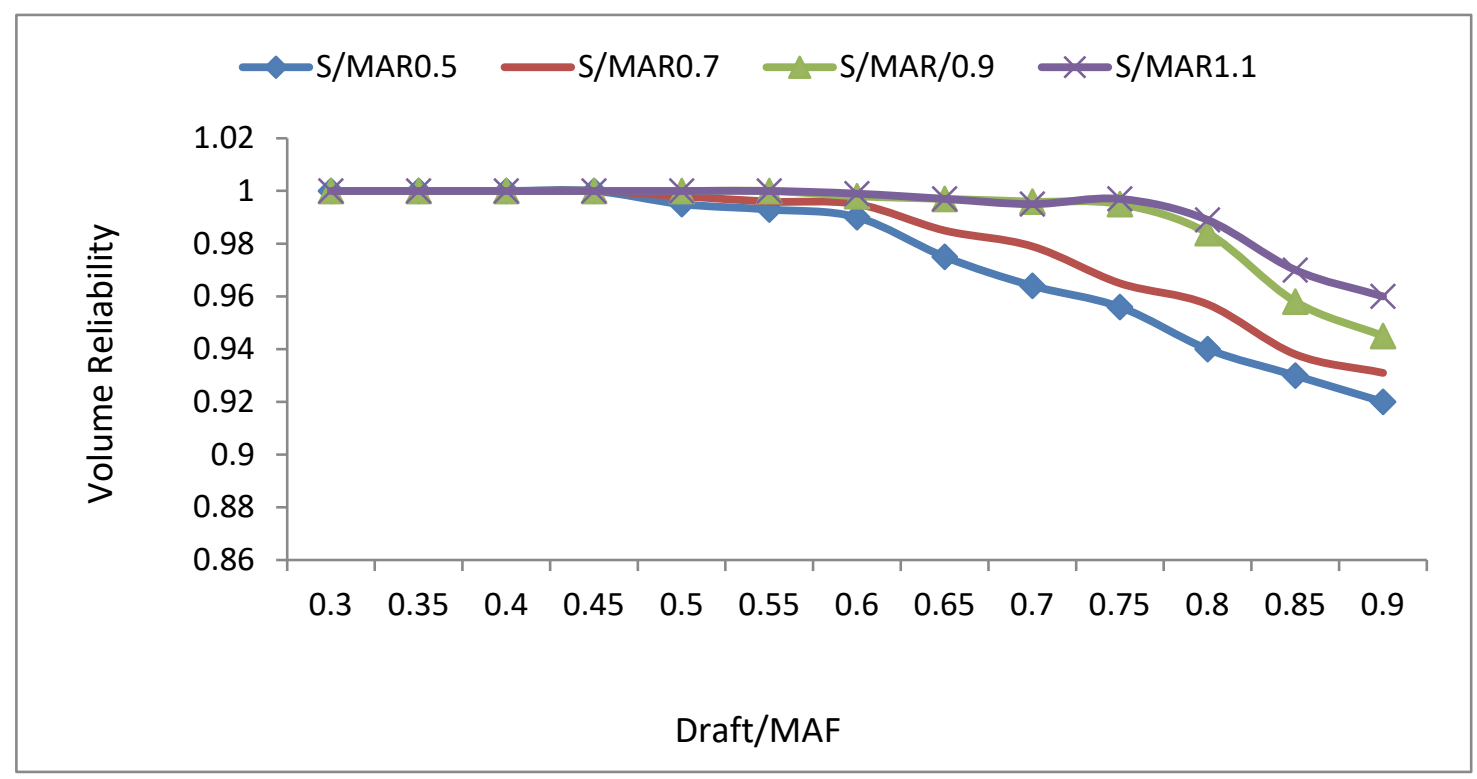

Figure 3.9. Variation of volume reliability with draft ratio

Figure 3.9 expresses volume reliability as a function of draft/MAR for diverse values of storage ratios. In this case volume reliability falls repeatedly as draft/ MAR upsurges and bigger values are gotten as S/MAR grows. It imperative to observe that the gap that exist between the curve for storage fractions of 0.7 and 0.9 are more juxtaposed to that between 0.5 and 0.7 , etc. The implication of this is that the larger storage is provided, then improvements in reliability are increasingly smaller. This agrees with the reservoir SLOP recalibrated policy of need to increase storage for better performance. This also means that the antecedent operating policy is less effective owing to its lower storage levels and consequently leading to higher vulnerability $(0.072)$ especially at higher demand levels. 
(ii) Sustainability Index

Figure 3.10 depict the relationships between sustainability index and draft as a ratio of the mean annual runoff.

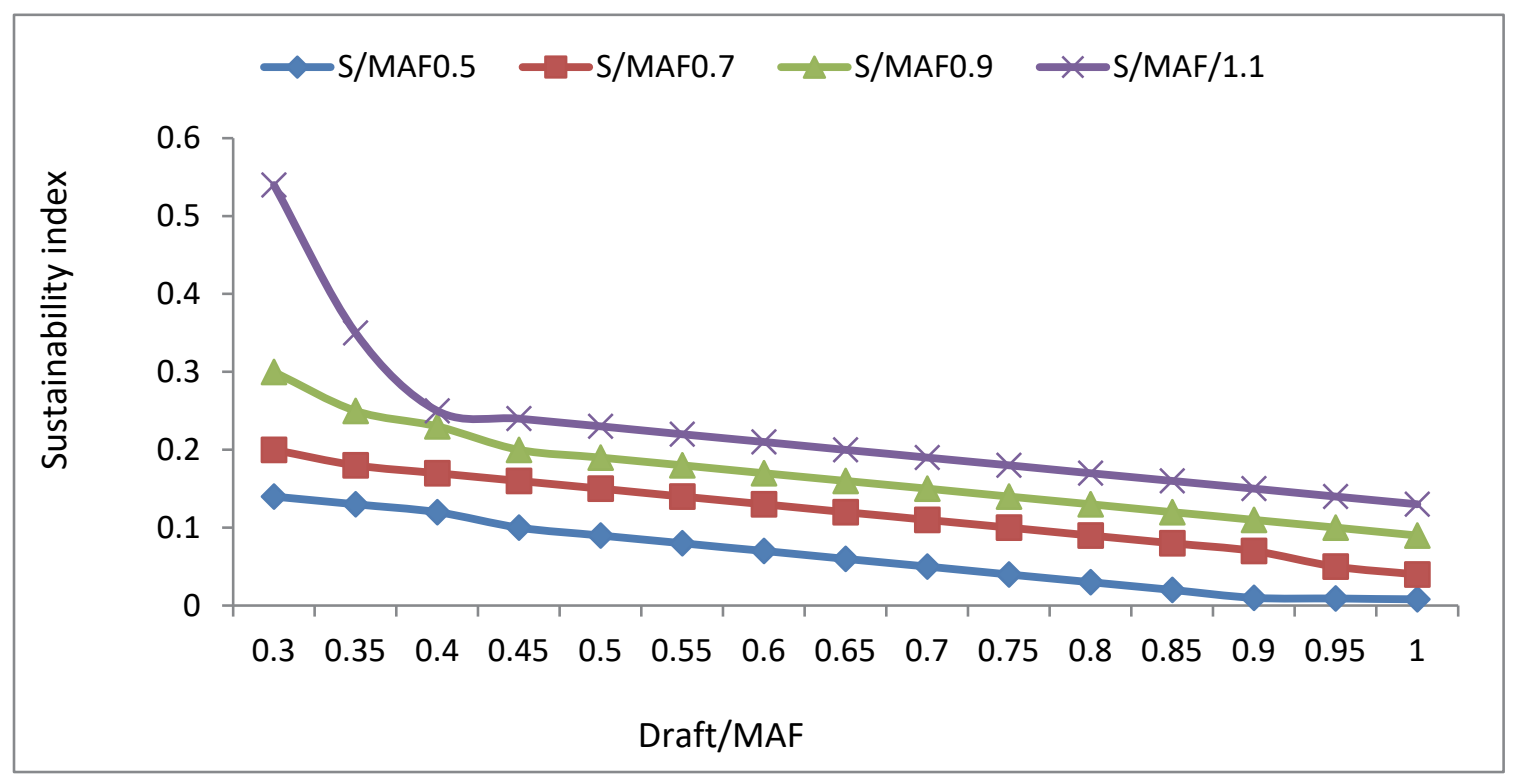

Figure 3.10. Variation of sustainability index with draft ratio

The figure 3.10 shows that as demand decreases the sustainability increases and the higher the storage ratio the higher the sustainability index. The figure shows that sustainability index has a monotonic variation with draft ratio. Figure 3.10 substantiate the recalibrated SLOP policy indicating the need for increase in storage ratio during months of incipient rainfall and low flow and during periods of high flow in preparation for the dry periods. This also indicates that the antecedent reservoir operating policy is less sustainable $(0.54)$ owing to its lower storage levels.

(iii) Resilience

Resilience (m) describes how quickly a system is likely to recover from failure. Figure 3.11: shows the variation of resilience with draft ratio. 


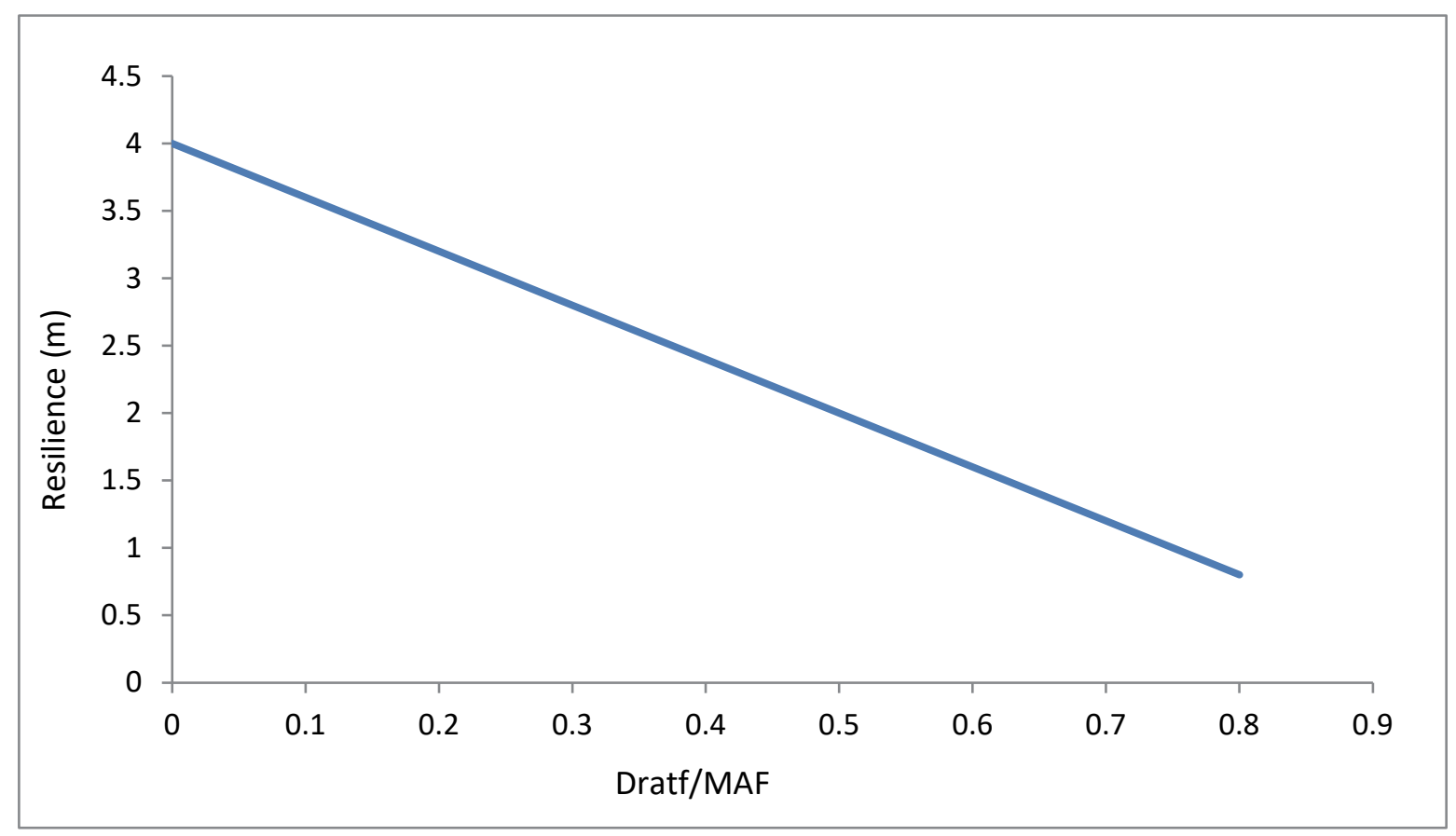

Figure 3.11. Variation of resilience with draft ratio

Figure 3.11 depicts the relationship between the resilience index and the draft ratio, it shows that as draft ratio increases the resilience decreases, and as the draft ratio decreases the resilience increases. This is imperative relating to the SLOP recalibrated reservoir policy depicting increase in the storage ratio, increase in storage ratio increase the reliability of reservoir system this substantiate the output of the recalibrated policy. The computed parameters of reservoir indices are presented in table 3.2 below.

Table 3.2 Reservoir Performance Indices

\begin{tabular}{llllll}
\hline Index & Draft Ratio & $\begin{array}{l}\text { Antecedent reservoir } \\
\text { Parameter Volicy }\end{array}$ & Index & $\begin{array}{l}\text { SLOP recalibrated } \\
\text { Parameter Values (\%) }\end{array}$ & Index \\
\hline Reliability & 0.75 & 0.92 & 0.96 \\
Sustainability & 0.75 & 0.54 & 0.76 \\
Vulnerability & 0.75 & 0.072 & 0.036 \\
Resilience & 0.75 & 1 & 1 \\
Volume & 0.75 & 0.95 & 0.99 \\
Reliability & & & &
\end{tabular}

\subsection{Classification of Reservoir System}

The result of the reservoir classification or characterisation is as presented in Table 3.3 below. 
Table 3.3 Values of Resilience (m), Demand level ( $\alpha$ ), and Coefficient of Variation

(CV) Obtained to Characterise the Reservoir System

\begin{tabular}{llll}
\hline Demand Level $(\alpha)$ & Coefficient of variation $(\mathrm{CV})$ & Resiliency $(m)$ & Characterization \\
\hline 0 & 0.25 & 4 & Within year \\
0.2 & 0.25 & 3.2 & Within year \\
0.4 & 0.25 & 2.4 & Within year \\
0.6 & 0.25 & 1.6 & Within year \\
0.8 & 0.25 & 0.8 & Over year \\
\hline
\end{tabular}

Table 3.3 shows the characterization of the reservoir system, the reservoir system is characterized as within year system considering the reservoir characterization limit condition that if $(m>1)$ and the coefficient of variation is low, the reservoir is within year system. The resilience indices $m$ increases with reduction in the demand level which depicts that the higher the demand level the less the reservoir resilience.

\section{Conclusion}

From the study it could be concluded that;

1. The extreme events of the rail fall are between September and January while the reservoir flows are between May and September.

2. The reservoir is less vulnerable, resilient and sustainable

3. The classification of the reservoir system as within year system is an indication of resiliency, and sustainability.

4. The higher the demand level the more vulnerable, less resilient, and less sustainable the reservoir hence the need for optimization of the operation rule.

\section{References}

Abdulkadir, I. S., Salami, A. M., Anwar, A. D., \& Kareem, A. G. (2013). Modelling of Hydropower Reservoir Variables for Energy Generation: NeuralNetwork Approach. Ethiopian Journal of Environmental Studies and Management, 6(3), 39 -49. http://dx.doi.org/10.4314/ejesm.v6i3.12

Adeloye, A. J., \& Montasari, M. (1999). Predicting Critical Period to Characterise Over-Year and Within-Year Reservoir Systems. Water Resource Management, 13, 383- 407.

Bhunya P. K., \& Jain S. K. (2010). Reliability, resilience and vulnerability of a multipurpose storage reservoir / Confiance, résilience et vulnérabilité d'un barrage multi- objectifs. Hydrological Sciences Journal Publication details, including instructions for authors and subscription information. Retrieved from http://www.tandfonline.com/loi/thsj20

Dukiya, J. I. (2013). Spatial Scrutiny of the Impacts of Kainji Hydropower Resevoir on the Down Stream Communities an Overview. A Journal of Geoinformatics and Geostatist, 4(4), 105-113.

Hashimoto, I., Loucks, D.H., Stedinger, D. (1982). dependability, resilience and vulnerabilityfor water resources system performance evaluation. Water Resources Research, 18 (1), 14- 20.

Hui., Z., Dedi, L., Shenglian, G., Lihua, X., Pan, L., Jiabo, Y., Yujie, Z., Jiayu, Z., \& Youjiang, S., (2019). Quantitative assessment of adaptive measures on optimal water resources allocation by using reliability, resilience, vulnerability indicators. Stochastic Environmental Research and Risk Assessment. 34, 103-119 (2020). https://doi.org/10.1007/s00477-019-01753-4

Issa S.T., Rozi M., and Majid, R. (2014). The critical period of reservoir systems considering performance indices on Malaysia Rivers. International Journal of Engineering \& $\quad$ Technology, $\quad 3(2), \quad$ 166-173. Science Publishing Corporation. Retrieved from www.sciencepubco.com/index.php/IJET 
Kang, R., Shengzhi, H., Qiang, H., \& Hao, W. (2019). Assessing the reliability, resilience and vulnerability of water supply system under multiple uncertain sources. Journal of Cleaner Production 252, 119806

Kjeldseen, T. G., \& Rosbjarg, W. (2004). Alternative reliability, resilience and Susceptibility estimators for risk assessments of water resources systems. Journal of Hydrology Science, 49(5), 755- 767.

Kundzewicz, Z. W., \& Laski, A. (1995) Reliability-related criteria in water supply system studies. In: New Uncertainty Concepts in Hydrology and Water Resources (ed. by Z. W. Kundzewicz). Cambridge University Press (in press).

Kundzewicz, Z. D., \& Kindler, T. (1995). various criteria for assessment of reliability aspects of water resources systems. In: Simonovic, S.P., 56-61.

Mc-Mahon, T. E., Adeloye, A. I., \& Zhou, S. (2006). Understanding performance procedures of Reservoirs, Journal of Hydrology, 324, 359-382.

Mohammed, J. M, Otache, Y. M, \& Jibril, I. (2018). Analysis and Characterization of Kainji Reservoir Inflow System. Environ Anal Eco stud, l(1). $\quad$ EAES.000504. 2018. http://dx.doi.org/10.31031/EAES.2018.01.000504

Moy., W. E., Cohon, J. R., ReVelle, C. G. (1986). A programming model for analysis of the reliability, resilience, and susceptibility of a water supply reservoir. Water Resources. Research, 22(4), 467- 498.

Oyebande, R., \& Balogun, F. (1992). Water Resources organisation in the Semi-arid Areas of Northern Nigeria. Cannadian. Journal of Development Studies Special Issue, 209-226.

Richard, M. J. T., \& Mc-mahon, A. (1996). Hydrological Sciences -Journal-Des-Sciences Hydrologiques, 41(1).

Sharad, K. F., \& Jain, D. (2010). Investigating the performance of statistical indices for performance assessment of a reservoir. Journal of Hydrology. Indian Institute of Technology, Roorkee, 247667, India

Silva, A.H. \& Portela, F. N. (2012). Probablistic Assessment of Reservoir storage -Yield Interactions in Portugal Journal of Hydrological Engineering - American Society of Civil Engineering, (18), 562 -76.

Suleiman, Y. D. (2013). Effect of Climate on Hydropower Generation in the Lower Niger -River Basin, Nigeria. Unpublished Ph. D Thesis, Department of Geography and Environmental Studies, University of Ilorin, Nigeria.

Suleiman, Y. I. M., \& Fabiyi, I. P. (2014). Afrrevv Stechnology, an International Journal of Science and Technology Bahirr Darr, Ethiopia, 3(2), 19-30. http://dx.doi.org/10.4314/stech.v3i2.2

Thomas, A. M., Adebayo, J. A., \& Sen-Lin, Z. (2005). Understanding performance measures of reservoirs. Journal of Hydrology, 324(2006), 359-382. http://www.elsevier.com/locate/jhydrol

Vogel, R. N., \& Bolognese, R. B. (1995). Storage-Reliability-Resistance-Yield Relations for Over-Year Water Supply Systems. Water Resources Research. (In Press).

Vogel, R. N., Lane, Y., Ravindrian, F. S., \& Kirshen, D. (1999). Storage - Reservoir Characteristics in the United States. Journal of Water Resources Planning and Management, American Society of Civil Engineers, 125(5), 246-257.

Vogel, R. G., \& Stedinger, J. N. (1987). Generalised- Storage-Reliability-Yield Interaction. Journal of Hydrology, $89,302-326$.

Yafang, C., Ping, F., Jianzhu, L., Yuangang, G., \& Peizhen, R. (2019). Water Supply Risk Analysis Based on Runoff Sequence Simulation with Change Point under Changing Environment. Advances in Meteorology, 2019, 16. https://doi.org/10.1155/2019/9619254.

Zongxue, Y., Jinno, J., Kawanura, N., Takesaki, C., \& Ito, F. (1998). Performance risk Scrutiny for Fukuokaa water supply system. Water Resources Management, 12, 14-32.

Zorica, S., \& Bojan, S. (2017). An Extension of the Sustainability Index Definition in Water Resources Planning and Management. Water Resour Manage. Springer. https://doi.org/10.1007/s11269-017-1609-6

\section{Copyrights}

Copyright for this article is retained by the author(s), with first publication rights granted to the journal.

This is an open-access article distributed under the terms and conditions of the Creative Commons Attribution license (http://creativecommons.org/licenses/by/4.0/). 